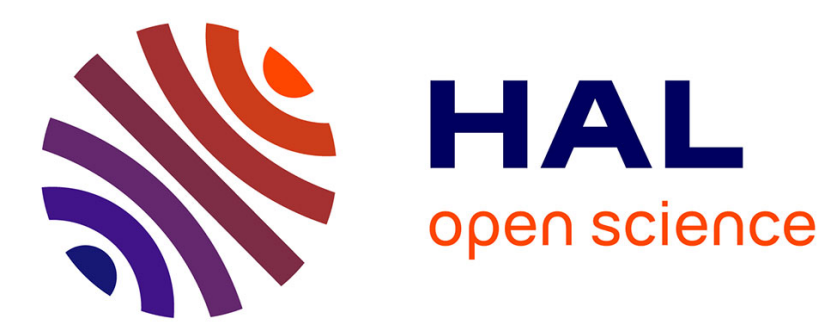

\title{
Nuclear waste storage and environmental intergenerational externalities
}

Mouez Fodha

\section{To cite this version:}

Mouez Fodha. Nuclear waste storage and environmental intergenerational externalities. International Journal of Sustainable Development, 2015, 18, pp.94. 10.1504/IJSD.2015.066792 . insu-01105358

\section{HAL Id: insu-01105358 \\ https://hal-insu.archives-ouvertes.fr/insu-01105358}

Submitted on 20 Jan 2015

HAL is a multi-disciplinary open access archive for the deposit and dissemination of scientific research documents, whether they are published or not. The documents may come from teaching and research institutions in France or abroad, or from public or private research centers.
L'archive ouverte pluridisciplinaire HAL, est destinée au dépôt et à la diffusion de documents scientifiques de niveau recherche, publiés ou non, émanant des établissements d'enseignement et de recherche français ou étrangers, des laboratoires publics ou privés. 


\title{
Nuclear Waste Storage and Environmental Intergenerational Externalities
}

\author{
Mouez Fodha*
}

January 2014

\begin{abstract}
This article analyzes the long-term consequences of nuclear waste storage within a general equilibrium framework. The objective is to determine the conditions for which the storage of waste, and thus the transfer of externalities towards the future, can be optimal. These conditions could explain the implementation of intergenerational externalities, justifying an intertemporal Not In My Back Yard behaviour. We first show that the choice of the policy instruments determines the feasibility of the storage policy. Indeed, economic stability imposes precise levels of the rate of storage or of the tax rate, making it possible to avoid chaotic economic dynamics. Under these specific conditions, and depending on the period at which an accident may occur and on the value of the social discount rate, we show that storing all the nuclear waste may be optimal.

Keywords: Overlapping Generations Model, Nuclear Waste, Environmental Externalities.

JEL Classifications: O13, Q53, Q58.
\end{abstract}

\section{Introduction}

World demand of energy is massively increasing and according to the Intergovernmental Panel on Climate Change, we can expect an increase in the demand of energy of more than $100 \%$ within fifty years. The depletion of the fossil fuel resources and the world fluctuations of the fuel prices led many countries to have recourse to the nuclear energy. Nuclear power can therefore be almost a part of the solution: it reduces the use of fossil energies (coal, oil, gas...); it reduces the Green House Gas emissions; it decreases the risk linked to energy dependence; and finally it protects against volatility of the international prices of resources. The European Union countries in general, France in particular, have chosen nuclear power for the production of long-term energy, thus making it possible to reach energy independence. Nuclear power energy is supposed to raise economic competitiveness and is part of the fight against climate change. Thus, $75 \%$ of the

\footnotetext{
*University of Orléans and Paris School of Economics. E-mail: mouezz.fodha@univ-orleans.fr.
} 
production of electricity in France is nuclear (of which a part is exported), and several countries have launched vast programs of nuclear energy production. Choosing nuclear power is a very long term engagement since we bequeath to future generations a heritage made up of parcels of waste, radioactive for thousands years.

Chakravorty et alii. (2012) show that, under some conditions on the technological process (like major developments in nuclear technology such as fast breeder reactors), the next generation nuclear power may supply significant amounts of clean energy. But, as these authors stated "Without these new nuclear technologies, the problem of waste accumulation becomes critical. Nuclear power may help us reduce atmospheric carbon, but will give rise to a new problem of storing significant amounts of toxic waste". The issue addressed in this paper concerns the management of the increasing nuclear waste stock. Indeed, the problem of the management of the nuclear waste has still not been solved. In France, for example, there is still no definitive technical solution for the future of this growing ${ }^{1}$ but non-desired production of waste. Basically, three techniques of treatment are operative:

- Storage of long duration (SLD) in industrial deposits or in old nuclear thermal power plants, or a few meters of depth under the natural level in an argillaceous formation of very low permeability, or more in-depth (old mine shaft);

- Storage (S) reversible or irreversible in deep geological repositories (argillaceous underground tanks). This storage is suitable for waste with high activity and long life, as their radioactivity present a strong thermal release problem. The deep geological repositories represent an environment which is a priori chemically, thermally and mechanically stable for geological scales of time (but without any certainty on the safety given the temporal scale). In addition, this storage makes it possible to be free from the high levels of permanent monitoring and maintenance which SLD requires.

- Separation then transmutation (ST) of the radioactive elements (decreasing the harmfulness and the lifespan of the radioactivity of waste). This technique admits a negative output since it requires more energy than that obtained by the fission which generated this waste.

Governments have to choose between two temporary solutions, (SLD and S); they hence face a trade-off between two risks: (i) risk of degradation of the protections of the parcels of waste (SLD) and (ii) risk of non-decrease of the radioactivity (S). But these two waiting strategies, (SLD) vs. (S), are not similar. In the first case (SLD), the present generations have to bear the harmful effects of these centres of nuclear waste storage. In the second case (S), waste disappear underground for several thousand years and reappear (i) voluntarily to be reprocessed like non radioactive waste, (ii) or involuntarily as a result of an accident; in both cases, future generations will have to bear these harmful effects. Making the choice of storage in deep geological repositories

\footnotetext{
${ }^{1}$ In the case of France, average annual production of radioactive waste increased by $20 \%$ in 20 years, passing from 1 to $1.2 \mathrm{~kg}$ per year per inhabitant (See CEA [2002]). It will in addition be necessary to manage the programme of dismantling first generation of nuclear power plants (28 nuclear plants out of the 56 existing).
} 
corresponds to behave according to the NIMBY ${ }^{2}$ principle but within an intertemporal framework. Several studies evaluate the willingness to pay (and/or to accept) for avoiding the proximity of the nuclear waste (see Riddel and Schwer (2006)): this willingness to pay is always positive, without any ambiguity, testifying the will to see waste moving away. Kunreuther and Easterling (1990) show in addition that when a public project, like that of nuclear waste processing, admits simultaneously positive and negative public components, monetary compensation is not enough to make people accept the proximity of the dangerous site. Acceptability requires the confidence of the agents concerned in the agencies of control and the belief in minimal risks. Given the temporal scale in which the management of the radioactivity fits, this approach cannot be exploited since the generations concerned by the harmful effects of the storage have not yet been born.

The objective of this paper is to determine the conditions for which the storage of waste, and thus the transfer of the externalities towards the future, can be optimal from a neoclassical economics point of view. The existence of these conditions would justify the implementation of intergenerational externalities, called here intertemporal NIMBY. The static resolution of the spatial dimension of the conflicts induced by NIMBY behavior was carried out by Feinerman et alii (2004). The authors show that the choice of localization between two cities of a public bad by a government will be a function of the costs and social benefits of each site, but also of the weight of the lobbies on the decision makers and of the degree of corruption of the government. Concerning the long-term nuclear waste management, future generations can claim no lobby. Our approach is intertemporal and considers the removal of nuclear waste in the future.

Actually, the seminal papers of Allais (1947), Samuelson (1958) and Diamond (1965) on intergenerational transfers show that current and future generations have limited opportunities for trade or coordination of policies. In the context of sustainable development, these limitations may have dramatic consequences since they lower the incentive to protect the environmental quality whose primary benefit falls on future generations. In particular, if we consider egoistic agents who neglect the effect of their actions on later generations and only demand goods for their own benefit. If current generations do not internalize the effects of their actions on future generations, there is an intergenerational externality that distorts the demand for environmental quality.

There is a huge literature examining the relationship between economic growth, environmental quality and intergenerational equity. This paper relates to two strands of the literature: the literature examining sustainable growth in a risky world characterized by uncertainties on the long-term environmental consequences of our current economic behavior, and the literature looking at intergenerational externalities in environmental quality. This paper examines these two issues jointly.

The first branch of the literature analyzes the environmental consequences (like climate change,

\footnotetext{
${ }^{2}$ NIMBY (Not In My Back Yard) indicates the actions of associations for the defence of an environment which are opposed to an infrastructure degrading the quality of life of a district, without denying its intrinsic social utility, but disputing its establishment because of the harmful local effects which it creates. The construction of factories, motorways, prisons, centres of rehabilitation and detoxication or concert halls cause such opposition regularly.
} 
biodiversity losses, health) of economic growth and technological accidents in optimal growth models; the latter consider an infinitely-lived agent or an intertemporal social planner (Tsur and Zemel (1996), (1998), (2008)).

The second branch of the literature analyzes how intergenerational externalities affect environmental outcomes but without considering any risk or uncertainties. John and Pecchenino (1994), John et alii (1995) and Marini and Scaramozzinno (1995) explore how distortions in abatement decisions affect environmental quality, von Amsberg (1995) and Howarth (1991a) (1991b) show how the incompleteness of insurance markets can lead to poor environmental outcomes. In the context of natural resources, Solow (1974), (1986), Howarth and Norgaard (1990), (1992), and more recently Gerlagh and Keyzer (2001) (2003), Agnani et alii (2005) or Valente (2011) explore how the efficient resource extraction path is affected by the distribution of rights and assets across generations. The focus of this article is on how intergenerational externalities affect the government's decisions about nuclear waste processing; this focus distinguishes my paper from related work.

The objective of this paper is on understanding the effect of intergenerational externalities on long-term energy policies (namely, nuclear strategy), and, hence, we abstract from intragenerational externalities. We consider a myopic government and myopic agents that internalize the intragenerational externality but do not internalize the intergenerational distortions.

There are several possibilities for selfish individuals to raise their chances to achieve intergenerational equity. First, one could consider altruistic agents who care about their children. When individuals care about the utility of their children, they may demand more long-term environmental quality. Second, governments could introduce policies to internalize intergenerational externalities. Finally, intergenerational coordination mechanisms could link different generations to achieve intergenerational equity. Nevertheless, the optimality issue of these possibilities depend upon the choices of the value of the discount rate.

Obviously, the debate about discounting is of big importance for environmental concerns; it affects the intergenerational justice and the definition of sustainability. This debate on discounting is still open among economists. In general discounting reflects the price of time. This rate is important for consumers because it determines the intertemporal trade-off between present and future consumption; it is also important for producers, as it influences the intertemporal trade-off between investing or not. Basically, the concept of discounting is easily comprehended in financial terms, in an individual context. At a macroeconomic level, there may be confusion about discounting. Probably this confusion relies on the distinction between an individual psychological discount factor, or rate of time preference, representing individual impatience and a social discount rate, reflecting short-term acceptability of the social costs.

Regarding environmental long term issues, discounting welfare of the future generations seems unfair; and minimizing the long-term environmental costs of our present economic actions is probably unfair too. These issues about discounting and intergenerational equity has been pointed 
out in two seminal papers. Howarth and Norgaard (1993) first show the important role played by the discount rate in cost-benefit analysis. They show that cost-benefit techniques will result in a Pareto efficient resource allocation only if the discount rate is set equal to the market rate of interest. They conclude that ethical principles should define the proper distribution of welfare between present and future generations. Krautkramer and Batina (1999) examine sustainability in overlapping generations models with resource constraints. They also show that economic efficiency depends on the value of the social rate of time preference.

This debate gives birth to a huge controversy after the publication of the Stern report (2006). Most criticisms targeted the choice of low values for the discount rate. ${ }^{3}$ As Godard (2009) pointed out "The results of a critical examination of this debate on discounting are that, for essential matters, the Stern Review is more right than wrong, in the context of the utilitarian philosophy that provides the conceptual basis of cost-benefit analysis used as well by Stern and his critics". It appears that the debates on the right climate policies to pursue enlighten a rather difficult and confused relationship between economics and ethics. Godard (2009) concludes that "For the future works, several avenues of progress have been identified, both within and outside utilitarianism, in order to find a more appropriate way to address huge long-term environmental threats like global climate change."

Hence, for ethical reasons and for intergenerational justice too, environmental economists have progressively abandoned the "pure neoclassical" discounting approach. Many reasons justify a non (exogenous) discounting approach, like irreversibility and uncertainty. ${ }^{4}$ Environmental economists have developed alternative criterions. Some recent papers propose neoclassical approaches with low or even non discounting criteria. ${ }^{5}$ Chichilnisky (1996) principle consists in a non-dictatorship of the present and non-dictatorship of the future. The objective function is a sum of two sub functions that take into account a discounted welfare and a very long-term non-discounted welfare. ${ }^{6}$ $\mathrm{Li}$ and Löfgren (2000) consider an objective function that takes into account the heterogeneity of agents (utilitarist and conservationist agents). The objective function is a sum of the two welfare functions: one is discounted, not the other. In Ayong Le Kama and Schubert (2004), the discount rate is endogenous and depends on the environmental quality at each period of time. Hence, impatience is low when pollution is high. A last approach adopts a social welfare function that takes into account uncertainty on economic variables, like consumption (Gollier (2002a)) or interest rate (Weitzman (1998)).

Basically, philosophers and mathematicians have proposed solutions to the discounting debates, mainly addressed to the issue of climate change (Gardiner (2004), (2006)), Portney and

\footnotetext{
${ }^{3}$ see for instance Nordhaus (2007) and Weitzman (2007).

${ }^{4}$ Gollier (2002a) (2002b) show that depending on the nature of risk preferences, one may optimally decrease the social discount rate.

${ }^{5}$ For survey, see for instance Groom et alii (2005), Pearce et alii. (2003), Portney and Weyant (1999) or Schubert (2006).

${ }^{6}$ See Chichilnisky and Heal (1998) for some applications of the Chichilnisky's principle.
} 
Weyant (1999), Caney (2008), Davidson (2012)), and some of them are specifically designed to treat the issue of nuclear waste (Shrader-Frechette (1994a), (1994b) and Taebi (2012)).

Regarding climate change, Gardiner (2004) (2006) draw attention to the ethical dimensions of the climate change problem, and claims that climate change is fundamentally an ethical issue. As such, it should be of serious concern to moral philosophers. Portney and Weyant (1999) shed light on the importance of the legacy that we may be leaving for future generations. They conclude that there will always be differing views on the appropriateness of discounting, not to mention the rate to use. Caney (2008) argues that we should see climate change as a threat to human rights and proposes an alternative to the cost-benefit analysis. Discounting is not recommended: Caney concludes indeed that the rights jeopardised by dangerous climate change do not diminish in importance throughout time. Finally, Shrader-Frechette (1994a) (1994b) and Taebi (2012) shed light on the fairness of present generations to impose the burden of nuclear waste on future generations. They both show that such decision is disputable as it relies on high long-term uncertainties. Indeed, putting distant future generations at a disadvantage does lack solid moral justification. This should urge us to reconsider our temporal moral obligations in the light of recent technological developments.

In this paper, we analyze the long-term consequences of burying nuclear waste within an overlapping generations models framework. This framework allows theoretical analysis of sustainability and led several works relating to the intergenerational environmental externalities. These studies show that the taking into account of myopic short-lived generations, increases the amplitude of the intertemporal externalities, and makes the task of the social planner more complex, requiring additional economic instruments.

Our results are in line with the previous ones: we show that the storage of the radioactive waste requires an institutional control of the production of this waste. Nevertheless, our objective is different from the ones of the previous studies, since we are interested neither in intertemporal allocation of natural resources, nor in the trade-off between growth and environmental quality. Our trade-off is that of the management of flows of pollution between present and future.

The model is presented in the second section of this paper. It relies on standard assumptions of the overlapping generations framework. The economy consists of two-periods lived agents. The government finances its spending for waste storage with help of a labour tax and a pollution tax. In the third section, we analyze the dynamic equilibrium and we show that in order to reach economic stability, the government has to control the waste storage activity. Hence, public policy for waste storage is needed in order to avoid chaotic development. In the fourth section, we characterize the long-term optimum: we show that the optimal level of capital is still lower than the ones defined by the (modified) golden rule. In section 5, we analyze the public policies that decentralize the optimal equilibrium. We show that depending on some parameter values (like the private and the social discount rates, or the cost of waste storage), conditions can be found to allow the government to store the whole nuclear waste at each period. Therefore, the 
intertemporal NIMBY behavior can be optimal, if optimality is defined in a Pareto-Walrasian way.

\section{The model}

We consider a perfectly competitive overlapping generations model with discrete time $t=1,2, \ldots, \infty$, and a constant population normalized to one. A generation of consumers is born at each period and households live two periods. When young, the representative consumer supplies labor, supposed to be inelastic and normalized to unity, and receives the net wage $\left(1-\tau_{t}^{w}\right) w_{t}$ where $\tau_{t}^{w} \in[0,1]$ is the tax rate on the wage $w_{t}$. He shares his wage between saving $s_{t}$ and consumption $c_{t}^{y}$. Let $T_{t}^{y}$ defines public transfer and $\tau_{t}^{k} \in[0,1]$ the tax rate on saving. When old, he consumes $c_{t+1}^{o}$ which represents the totality of his saving remunerated at the interest rate $r_{t+1}$. The agent cares about the quality of the environment measured by the index $Q_{t}$. The quality of the environment is an externality for the agent. ${ }^{7}$

We assume that the utility function consists of two increasing functions $u$ and $z$, strictly concave, homothetic and satisfy the Inada conditions. The utility function of the representative household at period $t$ is given by:

$$
U\left(c_{t}^{y}, Q_{t}, c_{t+1}^{o}, Q_{t+1}\right)=u\left(c_{t}^{y}, c_{t+1}^{o}\right)+\theta z\left(Q_{t}, Q_{t+1}\right)
$$

where $\theta \in[0,1]$ gives the weight of the quality of the environment on the utility. The two budget constraints faced by the household can be written:

$$
\mid \begin{aligned}
& \left(1-\tau_{t}^{w}\right) w_{t}-T_{t}^{y}=c_{t}^{y}+s_{t} \\
& c_{t+1}^{o}=\left(1+r_{t+1}\right)\left(1-\tau_{t+1}^{k}\right) s_{t}
\end{aligned}
$$

The representative consumer maximizes his utility function (1) under the constraints (2) and (3), which yields the necessary first order conditions determining the trade-off between present and future consumptions:

$$
u_{c^{y}}^{\prime}-\left(1+r_{t+1}\right)\left(1-\tau_{t+1}^{k}\right) u_{c^{o}}^{\prime}=0
$$

The final good is produced by a representative firm using constant returns to scale technology. The production is given by:

$$
\begin{aligned}
y & =f\left(k_{t}\right) \quad \text { with } f^{\prime}(.)>0 ; \quad f^{\prime \prime}(.) \leq 0, \\
f\left(k_{t}\right) & \left.=k_{t}^{\mu}, \text { with } \mu \in\right] 0,1[
\end{aligned}
$$

and where $y$ and $k$ are respectively the output per worker and the capital-labor ratio. The production function $f($.$) satisfies the Inada conditions.$

\footnotetext{
${ }^{7}$ This assumption is the main cause of intergenerational externalities; it implies that the households cannot adjust their behavior to the evolution of the perceived environmental quality. Assuming individual protection against pollution would enhance the results but it would also require numerical methods to solve the general equilibrium.
} 
The representative firm maximizes its profit:

$$
\underset{k_{t}}{\operatorname{Max}} \pi_{t}=f\left(k_{t}\right)-w_{t}-\left(1+r_{t}\right) k_{t}
$$

Since the economy is perfectly competitive, the profit maximization results to:

$$
\mid \begin{aligned}
& f^{\prime}\left(k_{t}\right)=1+r_{t} \\
& f\left(k_{t}\right)-k_{t} f^{\prime}\left(k_{t}\right)=w_{t}
\end{aligned}
$$

The storage of nuclear waste

We assume that a technology of storing waste is available in the economy represented by a function of projection $P^{i}$ such as:

$$
\forall x_{t}, \quad P^{i}\left(x_{t}\right)=x_{t+i}^{t}
$$

When the economy generates a flow of pollution $x_{t}$ at period $t$, the government can decide to store it until period $t+i$. The unit cost of the storage is measured by $\sigma$, which consists of development of the specific parcels of waste, cost of setting in basement, protective concrete

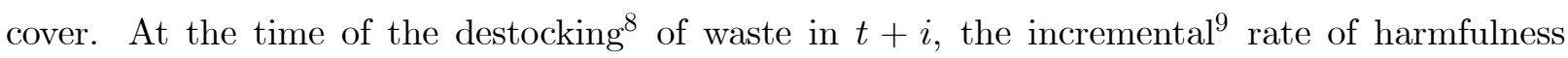
is unknown. This uncertain rate is $\tilde{\gamma}=(\underline{\gamma}, \bar{\gamma})$, where $\underline{\gamma} \in[0,1[$ and $P(\tilde{\gamma}=\underline{\gamma})=1-q$ with $q \in[0,1]$; also, $\bar{\gamma} \in[1,+\infty[$ and $P(\tilde{\gamma}=\bar{\gamma})=q$. The expected value of the rate of harmfulness is thus $E(\tilde{\gamma})=(1-q) \underline{\gamma}+q \bar{\gamma}$. This probability $q$ of high harmfulness could also be interpreted as the probability that one of the site of storage ${ }^{10}$ at period $t$ has an accident at period $t+i$.

A simple application will correspond to the case with $\underline{\gamma}=0$ (total disappearance of harmfulness), then we have $E(\tilde{\gamma})=q \bar{\gamma}$. If moreover $q \bar{\gamma}=1$, stored waste will be destocked in $t+i$ without additional harmfulness, they are simply projected in the future.

The total stock of waste stored must be finite in volume; it writes:

$$
S_{t}=\sum_{i=1}^{i=T} x_{t-i}<\infty
$$

\footnotetext{
${ }^{8}$ The destocking of waste can be voluntary (the physical limit of the capacities of storage is reached or the radioactivity is considered to be sufficiently low) or involuntary (natural wear at the end of periods $t+i$ ), even accidental.

${ }^{9}$ The rate of degradation of the environment by the production of waste is given for the economy. This constant rate will be affected in the future by the incremental rate: the rate of degradation of the environment in the future of waste produced in the present is thus unknown.

${ }^{10}$ At the period $t+i$, among 100 sites of storage of the generation $t, 100 q$ are confronted to important damages (accidents, leakages, explosions...). I actually assume a constant probability of accident. This is a limitation. Nevertheless, this probability of accident could be explained by two factors that play in opposite directions. The natural wear may deteriorate the storage repositories in the long-term but the technical progress may help the storage to get safer in the future. I assume that the technical progress compensates for the natural wear.
} 


\section{The evolution of the quality of the environment}

The production of nuclear power generates a flow of waste $F P_{t}$ which degrades the index of environmental quality. More precisely, this loss of amenities is explained by the two following types of processing waste: (i) Storage of long duration (SLD) in industrial repositories, which degrades the landscape and involves in particular losses in real value. (ii) Separation then transmutation (ST), which creates new waste not (or less) radioactive but which requires a great quantity of energy, which generates new radioactive waste.

The storage in deep geological repository of a share $\alpha$ of the waste during $i$ periods makes it possible to decrease his harmful effects for the present generations ${ }^{11}$, since on the one hand, the storage is carried out under several hundred meters under ground what makes the parcels of waste invisible, and on the other, after $i$ periods, the process of treatment will be probably simpler and less expensive in energy, because of the decrease of the radioactivity. Nevertheless, these strategies do nothing than to project in the future the contemporary externalities since the basement has limits of storage. Moreover, taking into account the present state of technological knowledge, on a long temporal scale (beyond 1000 years), it is not excluded that the erosion of the walls of the parcels of waste by the water yields the diffusion of the active radionuclide via the ground water.

We assume that, at each date, the economy rejects a flow of solid waste proportional to the capital:

$$
F P_{t}=\phi k_{t}
$$

where $\phi>0$ is the rate of degradation of the environment.

The dynamic of the quality of the environment is given by:

$$
Q_{t+i+1}=\tilde{Q}+[1-h] Q_{t+i}-(1-\alpha) F P_{t+i}-E(\tilde{\gamma}) P^{i}\left(\alpha F P_{t}\right)
$$

where $h \in[0,1]$ represents autonomous rate of variation of the quality of the environment ${ }^{12}$, $\alpha \in[0,1]$ is the share of the current flow of pollution that the government decides to store in deep geological repository in $t$ for $i$ periods, while waiting for the decrease of the radioactivity. We suppose that, at the period $t$, the oldest stocks are destocked in chronological order. The destocking can be voluntary (in the case of reversible storage) if the government estimates that the radioactivity of the parcels of $t-i$ is sufficiently low while he has to store the waste of $t$ (more radioactive) and being given limit of the total volume of storage capacities (the government manages substitutions in the geological tank of non-radioactive waste by radioactive waste). The destocking can also be accidental (in the case of irreversible storage) reflecting the existence of a rate of depreciation of protections coming from natural erosion (corrosion of the protections by water and compressing of the concrete structures). The oldest parcels are most vulnerable

\footnotetext{
${ }^{11}$ We do not consider the risk in $t$ bearing on the totality of the stocks hidden between $t-i$ and $t$ : risk coming from natural disasters, explosions, climatic change, air crashes... This risk is higher since the storage period $i$ is at a scale of several thousands years.

${ }^{12}$ The term $h$ can be interpreted as the capacity of assimilation of the environment.
} 
representing a natural process which answers chemical laws. In these two cases, the government cannot intervene any more on pollution since this one became diffuse.

Taking into account the sources of pollution the dynamic of the quality of the environment can be written:

$$
Q_{t+i+1}=\tilde{Q}+[1-h] Q_{t+i}-(1-\alpha) \phi k_{t+i}-((1-q) \underline{\gamma}+q \bar{\gamma}) \alpha \phi k_{t}
$$

The government uses the taxes on labor and capital to finance the cost of storing waste and lump-sump transfers, $T_{t}^{y}$, allow balancing the budget:

$$
\sigma \alpha \phi k_{t}=\tau_{t}^{k}\left(1+r_{t}\right) s_{t-1}+\tau_{t}^{w} w_{t}+T_{t}^{y}
$$

The goods market equilibrium is given by:

$$
y_{t}=c_{t}^{y}+c_{t}^{o}+k_{t+1}+\sigma \alpha F P_{t}
$$

This market equilibrium takes into account the economic cost of storing the waste.

The labor market equilibrium is given by $L_{t}=N_{t}$.

The Walras law allows deducing the capital market equilibrium:

$$
k_{t+1}=s_{t}\left[\left(1-\tau_{t}^{w}\right) w\left(k_{t}\right)-\left(1-\tau_{t+1}^{k}\right)\left(1+r\left(k_{t+1}\right)\right)\right]
$$

A competitive equilibrium for this economy is a sequence $\left\{y_{t}, k_{t}, c_{t}^{y}, c_{t}^{o}, s_{t}, w_{t}, r_{t}, T_{t}^{y}, \tau_{t}^{w}, \tau_{t}^{k}\right\}_{t=1}^{\infty}$, such that, at each date $t=1,2, \ldots$,

(i) agents maximize (1) subject to (2);

(ii) firms maximize profits;

(iii) markets clear;

(iv) the quality of the environment evolves according to the law (9);

and $\left\{k_{0}, Q_{0}\right\}$ are given.

\section{Dynamic equilibrium analysis}

Let define $\eta_{c}$ a parameter of preference elasticity: $\left.\eta_{c}=\frac{c^{o}}{c^{y}} \frac{u_{c o}^{\prime}}{u_{c y}^{\prime}} \in\right] 0, \infty[$, which is supposed to be constant. This assumption limits the utility functional forms to some forms like the logarithmic 
and the Cobb-Douglas cases. The equation (3) becomes after substitution of the equation of the capital market equilibrium (13):

$$
c_{t}^{y}=\frac{1}{\eta_{c}\left(1+r_{t+1}\right)\left(1-\tau_{t+1}^{k}\right)} c_{t+1}^{o}
$$

Taking into account (2), we have:

$$
c_{t}^{y}=\frac{1}{\eta_{c}} k_{t+1}
$$

From the budget constraints and the prices relations we find:

$$
c_{t}^{y}=\left(1-\tau_{t}^{w}\right)(1-\mu) k_{t}^{\mu}-k_{t+1}-T_{t}^{y}
$$

Equalizing (15) and (16), we obtain:

$$
k_{t+1}=\frac{\eta_{c}}{1+\eta_{c}}\left[\left(1-\tau_{t}^{w}\right)(1-\mu) k_{t}^{\mu}-T_{t}^{y}\right]
$$

From the budget equilibrium of the government (11), with the equilibrium conditions and the price relations, we can write:

$$
T_{t}^{y}=\sigma \alpha \phi k_{t}-\mu \tau_{t}^{k} k_{t}^{\mu}-(1-\mu) \tau_{t}^{w} k_{t}^{\mu}
$$

Substituting equation (18) into (17), we obtain the dynamic of the capital stock:

$$
k_{t+1}=\frac{\eta_{c}}{1+\eta_{c}}\left(\left(1-\mu\left(1-\tau_{t}^{k}\right)\right) k_{t}^{\mu}-\sigma \alpha \phi k_{t}\right)
$$

Thus, we have a first-order nonlinear difference equation, which with equation (10), determine the dynamic of the economy. The dynamic of the stock of capital being autonomous, we can analyze independently their properties. Since the stock of capital enters linearly into the dynamic of the quality of the environment, the dynamic properties of the quality of the environment can then be deduced.

The dynamic of the stock of capital can be rewritten:

$$
k_{t+1}=a_{1} k_{t}^{\mu}-a k_{t} \equiv G\left(k_{t} ; \tau_{t}^{k}, \sigma, \alpha, \phi\right)
$$

where $a_{1}=\frac{\eta_{c}}{1+\eta_{c}}\left(1-\mu\left(1-\tau_{t}^{k}\right)\right)>0$ and $a=\frac{\eta_{c}}{1+\eta_{c}} \sigma \alpha \phi \geqslant 0$. The properties of this equation will depend on the level of $\sigma \phi \alpha$ measuring the marginal cost of storing waste, $\sigma \phi \alpha k_{t}$ being the total cost. The equation (22) is nonlinear and it is straightforward to show that the $G$ map satisfies the following conditions:

$[P .1] G(0)=G(\widehat{k})=0$, where $\widehat{k}=\left(\frac{a_{1}}{a}\right)^{\frac{1}{1-\mu}}$ is the upper bound of the stock of capital $k$;

$[P .2] G$ is once continuously differentiable and there exists $\bar{k}=\left(\frac{\mu a_{1}}{a}\right)^{\frac{1}{1-\mu}}$ such that $G$ is strictly increasing on $[0, \bar{k})$ and strictly decreasing on $(\bar{k}, \widehat{k}]$; 
[P.3] $\lim _{k \rightarrow 0} G^{\prime}(0)=+\infty$;

$[P .4]$ the unique positive steady state equilibrium is given by $k^{*}=\left[\frac{a_{1}}{1+a}\right]^{\frac{1}{1-\mu}}$;

$[P .5] G^{\prime}\left(k^{*}\right)=\mu-a(1-\mu)<1$ since $a>0$ and $\left.\mu \in\right] 0,1[$;

$[P .6]$ If $a>=<\frac{\mu^{-\frac{\mu}{1-\mu}}}{1-\mu}, G(\bar{k})>=<\widehat{k} ; G$ maps $[0, \widehat{k}]$ into itself if $a \leq \frac{\mu^{-\frac{\mu}{1-\mu}}}{1-\mu}$.

The property $[P .6]$ implies that there exists circumstances in which $G$ does not map $[0, \widehat{k}]$ into itself, thereby admitting more complicated dynamic structure. We can distinguish two different dynamic structures with respect to the value of $a$.

Case 1: $a \leqslant \frac{\mu^{-\frac{\mu}{1-\mu}}}{1-\mu}$

In this case $G$ maps $[0, \widehat{k}]$ into itself. That means, any iterates of the set of an initial capital stock will remain in the interval. In that case, the dynamic system may exhibit a series of bifurcation, including the appearances of cycles and the transition to aperiodic or chaotic behavior. When $a$ is not very high, there exists a unique steady state characterized by $k^{*}=\left[\frac{a_{1}}{1+a}\right]^{\frac{1}{1-\mu}}$.

Proposition 1 (i) If $a \in\left(0, \frac{\mu}{1-\mu}\right]$, for all $k_{0} \in(0, \widehat{k}), \lim _{t \rightarrow \infty} G^{t}\left(k_{0}\right)=k^{*}$. $k^{*}$ is a stable node. (ii) If $a \in\left(\frac{\mu}{1-\mu}, \frac{1+\mu}{1-\mu}\right]$, then for all $k_{0} \in(0, \widehat{k}), \lim _{t \rightarrow \infty} G^{t}\left(k_{0}\right)=k^{*} . k^{*}$ is a stable spiral.

The relevant parameter ranges for $a$ are given by the two cases for which the slopes of $G$ evaluated at the fix point $k^{*}$ belong to $G^{\prime}\left(k^{*}\right) \in(0, \mu)$ and $G^{\prime}\left(k^{*}\right) \in(-1,0)$. Indeed, we have:

$$
G^{\prime}\left(k^{*}\right)=\mu-a(1-\mu)=\left\{\begin{array}{ccc}
0 & \text { if } & a=\frac{\mu}{1-\mu} \\
\mu & \text { if } & a=0 \\
-1 & \text { if } & a=\frac{1+\mu}{1-\mu}
\end{array} .\right.
$$

Since $a=\frac{\eta_{c}}{1+\eta_{c}} \sigma \phi \alpha$, the feasibility of the policy of storing waste is conditional to the dynamics of capital stock. According to the level of the marginal cost of storing waste, the government will choose a level of storage (then a tax rate to finance it) which will determine the dynamic of the economy. The government can then avoid a chaotic dynamic ${ }^{13}$ and controls the trajectory of pollution and nuclear waste, whatever are the initial conditions.

From Zhang (1999) and the literature on nonlinear dynamics (Devaney (2003)), we can establish the following propositions 2 and 3, which determine the conditions for the appearance of n-period cycles, in particular the 2-period and 3-period cycles.

\footnotetext{
${ }^{13}$ When the dynamic of the stock of capital is chaotic, then the dynamic of the emissions of nuclear waste is also chaotic since $F P_{t}=\phi k_{t}$.
} 


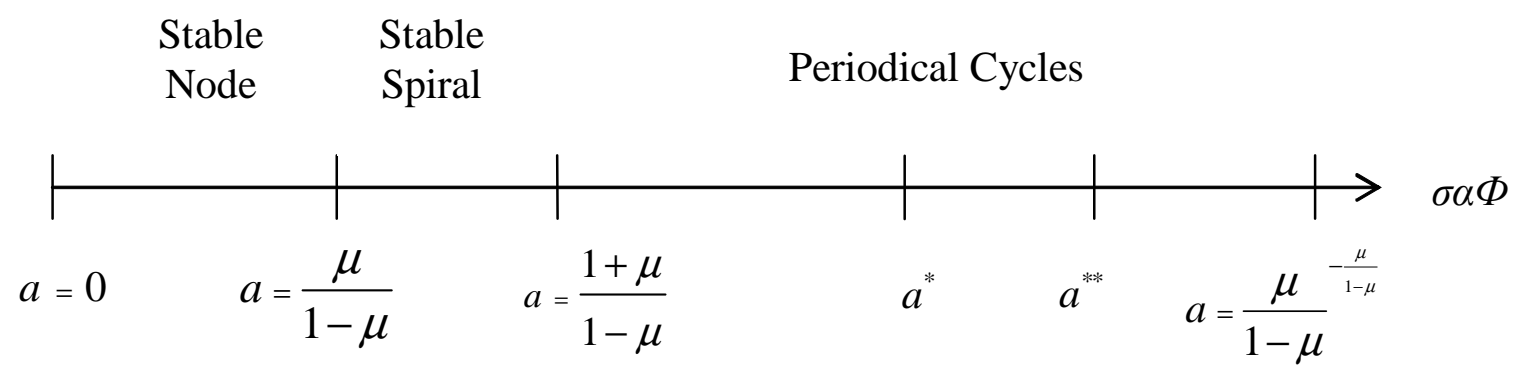

Figure 1:

Proposition 2 ( $i$ ) If $a \in\left(\frac{1+\mu}{1-\mu}, \frac{\mu^{-\mu /(1-\mu)}}{1-\mu}\right)$, map $G$ generates a two-period cycle, and the set of $k_{0} \in(0, \widehat{k})$ such as $G^{t}\left(k_{0}\right)$ converges to the steady state, $k^{*}$, is at most countable. (ii) As $a$ rises, the dynamic system (18) experiences period-doubling or flip bifurcations. That is, there exists a value of $a, a^{*} \in\left(\frac{1+\mu}{1-\mu}, \frac{\mu^{-\mu /(1-\mu)}}{1-\mu}\right)$ such that attracting cycles of period $2^{n}$, for $n \geq 2$, emerge; ( $i i i)$ for higher value as further rises of $a$, there exists a value of $a$, $a^{* *} \in\left(\frac{1+\mu}{1-\mu}, \frac{\mu^{-\mu /(1-\mu)}}{1-\mu}\right)$ such that period 3 cycle of $G$ emerges if $a>a^{* *}$.

Proposition 2 is similar to proposition 3 of Zhang (1999) since map $G$ has the same form than the one in his paper. This proposition suggests that as $a$ rises, the set of equilibriums evolves from endogenous fluctuations to chaotic equilibriums, passing through periodic equilibriums (see Fig. 1). The property of the dynamic and the characteristic of equilibriums evolve according to the values of $\sigma, \alpha, \phi$ : higher are the marginal cost $\sigma$ and the burying rate $\alpha$, more chaotic equilibriums can appear.

Case 2: $a>\frac{\mu^{-\mu /(1-\mu)}}{1-\mu}$

When $a$ is successively raised to some high values, the topological structure under this case is much more complicated than under the previous case, and the results can be summarized by proposition $3^{14}$.

Proposition 3 If $\mu^{\mu}[(1-\mu) a-1]^{(1-\mu)}>(a-1) / a$, the set of an initial capital stock that never escapes from $(0, \widehat{k})$ is a Cantor set; that is, it is a closed, totally disconnected, and perfect subset of $(0, \widehat{k})$. As a result, given any initial value, the subsequent transitional dynamics for $k$ become very complex.

\footnotetext{
${ }^{14}$ Proposition 3 is also similar to proposition 4 of Zhang (1999) for the same reason of similarity of map $G$.
} 


\section{Long term optimum}

Assume the existence of a social planner maximizing the utility of all generations discounted by a social discount factor $\delta(0<\delta<1)$. The social planner programme writes:

$$
\max _{c_{t}^{y} ; c_{t+1}^{o} ; Q_{t} ; k_{t}} \sum_{t=1}^{+\infty} \delta^{t-1}\left(u\left(c_{t}^{y}, c_{t+1}^{o}\right)+\theta z\left(Q_{t}, Q_{t+1}\right)\right)
$$

under the constraints:

$$
\mid \begin{array}{cc}
y_{t}=c_{t}^{y}+c_{t}^{o}+k_{t+1}+\sigma \alpha \phi k_{t} & (\forall t=1, \ldots,+\infty) \\
Q_{t+1}=\tilde{Q}+[1-h] Q_{t}-(1-\alpha) \phi k_{t}-((1-q) \underline{\gamma}+q \bar{\gamma}) \alpha \phi k_{t-i} & (\forall t=1, \ldots,+\infty) \\
y_{t}=f\left(k_{t}\right) & (\forall t=1, \ldots,+\infty)
\end{array}
$$

$k_{0}$ and $Q_{0}$ given.

To the resource constraint of period $t$ is associated the multiplicator $\delta^{t} \lambda_{1, t}$; the planner takes into account the cost of storing waste on the allocation of resource, which reduces consumption and investment possibilities. To the quality of the environment dynamic $Q_{t}$ is associated the multiplicator $\delta^{t} \lambda_{2, t}$. Then we can find the following relation ${ }^{15}$ :

$$
\lambda_{2}=\frac{(1-h) \theta z^{\prime}(1+\delta)}{1-\delta(1-h)}>0
$$

where $\lambda_{2}$ is the shadow price of the quality of the environment. It allows to define the marginal social benefit of the variation of the quality of the environment and must equal the discounted value of the marginal utility of the environment. Thus, $(1-h) \theta z^{\prime}$ represents the long-term impact of the environment for the coexisting two generations, $\delta$ being the discounting term. One can remark that the result is consistent with the relevant discount rate for environment policies defined by Marini and Scaramozzino (1995), which is equal to the sum of the social discount rate $\frac{1}{\delta}-1$ and the rate of natural assimilation $h$.

We can determine the capital shadow price $\lambda_{1}$ :

$$
\lambda_{1}=\frac{\Theta \frac{\theta z^{\prime}(1+\delta)}{1-\delta(1-h)}}{f^{\prime}-\sigma \alpha \phi-\frac{1}{\delta}}>0
$$

where $\Theta=\phi\left(1-\alpha\left(1-\delta^{i} E(\tilde{\gamma})\right)\right)>0$ is the average discounted rate of long-term pollutant emissions with $E(\tilde{\gamma})=(1-q) \underline{\gamma}+q \bar{\gamma}$.

The marginal effect of storing waste on the long-term well-being is measured by $\Theta z^{\prime} \frac{\theta}{1-\delta(1-h)}$. This marginal effect, depending on the average discounted rate of pollution, can be either positive

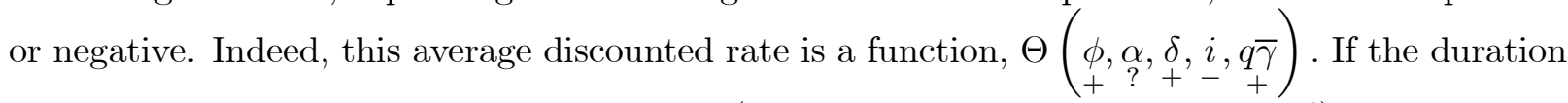
of storage increases, the discounting effect (corresponding to lower values of $\delta$ ) decreases the

\footnotetext{
${ }^{15}$ The resolution is presented on appendix, page 20 .
} 
pollution consequences on welfare, $\Theta_{\delta}^{\prime}>0$. The effect of storing waste depends on the sign of $1-\delta^{i} E(\tilde{\gamma})$. If $\delta^{i} E(\tilde{\gamma})>1$, the long-term storage degrades more the quality of the environment than the amelioration it is supposed to do: $\Theta_{\alpha}^{\prime} \geqslant 0$. In the opposite, if $\delta^{i} E(\tilde{\gamma})<1$, the storage allows to pollute less than it protects: $\Theta_{\alpha}^{\prime}<0$. In the case where $E(\tilde{\gamma})=1$ and with a discount factor $\delta=1$, storing the waste will have no effect in the long term: $\Theta=\phi$.

The shadow price of the capital stock $\lambda_{1}$ is positive if and only if $f^{\prime}>\sigma \alpha \phi+\frac{1}{\delta}\left(=\hat{k}_{\text {orm }}^{v}\right)$. In the economy with pollution, the planner will choose a level of intensive capital lower than the one determined by the golden rule (Samuelson optimum), but also lower than the one of the modified golden rule.

The intergenerational trade-off rule defined by the social planner is given by:

$$
u_{c^{y}}^{\prime}=\frac{1}{\delta} u_{c^{o}}^{\prime}
$$

This rule expresses the optimal condition for the trade-off between $c^{y}$ and $c^{o}$. We can determine the expression of the optimal $\hat{c}^{y}$ and $\hat{c}^{o}$ using the conditions defined by (21), (22), (23). Using these expressions with the equilibrium condition of the goods market gives the following relation:

$$
f^{\prime}(\hat{k})=\theta \frac{1+\delta}{1-\delta(1-h)} \frac{\Theta z^{\prime}}{u_{c^{y}}^{\prime}}+\sigma \alpha \phi+\frac{1}{\delta}
$$

The planner maximization programme solution's can be summarized by the following system, which determines $\left\{\hat{c}^{y}, \hat{c}^{o}, \hat{k}, \hat{Q}\right\}$ :

$$
\begin{gathered}
u_{c^{y}}^{\prime}=\frac{1}{\delta} u_{c^{o}}^{\prime} \\
f^{\prime}(\hat{k})=\frac{\Theta \frac{\theta z^{\prime}(\delta+1)}{1-\delta(1-h)}}{u_{c}^{\prime} y}+\sigma \alpha \phi+\frac{1}{\delta} \\
f(\hat{k})=\hat{c}^{o}+\hat{c}^{y}+(1+\sigma \alpha \phi) \hat{k} \\
\hat{Q}=\frac{\tilde{Q}}{h}-\frac{\phi}{h}[1-\alpha(1-\{(1-q) \underline{\gamma}+q \bar{\gamma}\})] \hat{k}
\end{gathered}
$$

\section{The decentralized equilibrium}

The planner must propose the tax rates that allow the competitive equilibrium (system (29)) to coincide with the long term equilibrium (system (25)). There are two economic inefficiencies: $(i)$ the dynamic inefficiency leading to over or under-accumulation of capital; (ii) and the production of pollutant nuclear waste. The optimal tax-transfer scheme is composed by two instruments $\left(\hat{\tau}^{w}, \hat{\tau}^{k}\right)$. The tax policy allows to reach the capital defined by the Modified Golden Rule $\left(\hat{\tau}^{w}\right)$ and to internalize the flow of pollutants $\left(\hat{\tau}^{k}\right)$. A third instrument $\widehat{T}^{y}$ allows to balance the government budget. 
To reach the optimum, we must find the intergenerational trade-off rule (23) from the trade-off condition (3) evaluated at the steady state:

$$
\frac{1}{\left(1+r^{*}\right)\left(1-\hat{\tau}^{k}\right)}=\delta
$$

which yields the following value for $\hat{\tau}^{k}$ :

$$
\hat{\tau}^{k}=1-\frac{1}{\left(1+r^{*}\right) \delta} .
$$

In that case, since $\left(1+r^{*}\right)=f^{\prime}(\hat{k})$ at the optimum, we obtain the following optimal value for the tax rate:

$$
\hat{\tau}^{k}=1-\frac{1}{f^{\prime}(\hat{k}) \delta}=\frac{\delta \frac{\Theta \frac{\theta z^{\prime}(1+\delta)}{1-\delta(1-h)}}{u_{c}^{\prime} y}+\sigma \alpha \phi \delta}{1+\delta \frac{\Theta \frac{z^{\prime}(1+\delta)}{1-\delta(1-h)}}{u_{c y}^{\prime}}+\sigma \alpha \phi \delta}>0 .
$$

This tax allows to correct the environmental externality, its rate increases as the marginal environmental damage is high, $\Theta z^{\prime}$, with respect to the marginal utility of the consumption $u_{c^{y}}^{\prime}$.

The capital market equilibrium allows to determine the wage tax on the young $\hat{\tau}^{w}$. This relation is such that:

$$
\hat{k}=s\left(\left(1-\hat{\tau}^{w}\right) w(\hat{k})-\hat{T}^{y},\left(1-\hat{\tau}_{t+1}^{k}\right) f^{\prime}(\hat{k})\right) .
$$

This condition allows to fix the tax rate that corrects the dynamic inefficiency and then to reach the stock of capital defined by the Modified Golden Rule. Finally, the budget equilibrium condition determines the level of the lump-sump tax:

$$
\hat{T}^{y}=\hat{\tau}^{k} \mu \hat{k}^{\mu}+\hat{\tau}^{w}(1-\mu) \hat{k}^{\mu}-\sigma \alpha \phi \hat{k} .
$$

For a given level of $\hat{\tau}^{k}$, condition (28) defines the share of waste $\hat{\alpha}$ to store which is unique, and compatible with optimality. In that case, the government fixes the optimal rate of storage such that:

$$
\hat{\alpha}=\frac{\frac{\tau^{k}}{1-\tau^{k}}-B}{\delta \phi \sigma-B\left(1-\delta^{i} E(\tilde{\gamma})\right)}
$$

where $B=\delta \phi \frac{\theta \frac{z^{\prime}}{u_{c}^{\prime}}(1+\delta)}{1-\delta(1-h)}>0$.

For certain values of $\delta$ and $q$, this optimal share can be equal to unity. Therefore we can be in the particular case of total intergenerational NIMBY as $\hat{\alpha}=1$. The government decides to postpone all the pollution into the future to reach the social optimum. It would be the case if:

$$
\frac{\tau^{k}}{1-\tau^{k}}=\delta \phi \sigma+B \delta^{i} E(\tilde{\gamma})
$$

But the economic conditions allowing to avoid a chaotic dynamic bear on the parameter $a=\frac{\eta_{c}}{1+\eta_{c}} \sigma \phi \alpha$. Hence, it is necessary that $a$ should not be too high, which settles some bounds 
on $\hat{\alpha}$, corresponding to the feasibility of the economic policy. In fact, it is possible to reach stable solutions if:

$$
\begin{aligned}
a & \leqslant \frac{1+\mu}{1-\mu} \\
& \Leftrightarrow \quad \hat{\alpha} \leqslant \frac{\delta \phi \sigma-B\left(1-\delta^{i} E(\tilde{\gamma})\right)}{\frac{\tau^{k}}{1-\tau^{k}}-B} \frac{1+\eta_{c}}{\eta_{c}} \frac{1}{\sigma \phi} \frac{1+\mu}{1-\mu} .
\end{aligned}
$$

\section{Conclusion}

This paper analyzes the conditions for which the storage of waste, and thus the transfer of the externalities towards the future, can be optimal. If they exist, these conditions would justify the policy of projections in the future of present radioactive waste, in spite of uncertainty relating to future harmfulness. This environmental policy exacerbates the intergenerational externalities. These choices correspond thus to intertemporal NIMBY behaviors. We show that storing the radioactive waste requires an institutional control of the production of this waste, in order to avoid a not controlled evolution of it. Moreover, the choice of the regulatory instruments determines the feasibility of the policy. Indeed, the research of economic stability determines thresholds of rate of storage or rate of tax making it possible to avoid the chaotic evolutions. Lastly, the optimal choice of the public instruments does not exclude the possibility of storing all the waste for the government. This solution can be desirable according to, in particular, the duration envisaged of the storing and the value of the social discount rate. Indeed, the more the temporal horizon of destocking is remote and the more the perception of serious risk of future pollution decreases.

\section{References}

Agnani B., Gutierrez M.J., Iza A. (2005), "Growth in overlapping generation economies with nonrenewable resources," Journal of Environmental Economics and Management, 50, p. 387-407.

Allais M., (1947), Économie et Intérêt, Imprimerie Nationale, Paris.

Ayong Le Kama A., Schubert K. (2004), "Growth, Environment and Uncertain Future Preferences," Environmental and Resource Economics, 28(1), p. 31-53.

Caney S. (2008), "Human rights, climate change, and discounting," Environmental Politics, 17(4), Special Issue: Perspectives on Justice, Democracy and Global Climate Change.

CEA (2002), "Les recherches pour la gestion des déchets nucléaires, les résultats d'aujourd'hui, les solutions de demain...", CLEFS.

Chakravorty U., Magne B., Moreaux M. (2006), "Resource Use under Climate Stabilization: Can Nuclear Power Provide Clean Energy?", Journal of Public Economic Theory, 14(2), p. 349-389. 
Chichilnisky G. (1996), "An axiomatic approach to sustainable development," Social Choice and Welfare, 13(2), 231-257.

Chichilnisky G., Heal G. (1998), "A unified treatment of finite and infinite economies: limited arbitrage is necessary and sufficient for the existence of equilibrium and the core," Economic Theory, 12(1), p. 163-176.

Davidson M.D. (2012), "Intergenerational Justice: How Reasonable Man Discounts Climate Damage," Sustainability, 4(1), p. 106-122.

Devaney R.L. (2003), An introduction to Chaotic Dynamical Systems, Boston University, Ed.

Diamond P.A. [1965], "National Debt in a Neoclassical Model," American Economic Review, 55, p. $1126-1250$.

Feinerman, E., Finkelshtain I., Kan I. (2004), "On a Political Solution to the NIMBY Conflict", American Economic Review 94(1), pp. 369-381.

Gardiner S.M. (2004), "Ethics and Global Climate Change," Ethics, 114(3), p. 555-600.

Gardiner S.M. (2006), "A Perfect Moral Storm: Climate Change, Intergenerational Ethics and the Problem of Moral Corruption," Environmental Values, 15, p. 397-413.

Gerlagh R., Keyzer M. (2001), "Sustainability and the intergenerational distribution of natural resource entitlements," Journal of Public Economics, 79(2), p. 315-341.

Gerlagh R., Keyzer M. (2003), "Efficiency of conservationist measures: an optimist viewpoint," Journal of Environmental Economics and Management, 46(2), p. 310-333.

Godard O. (2009), "Time discounting and long-run issues: the controversy raised by the Stern Review of the economics of climate change," OPEC Energy Review, 33(1), p. 1-22.

Gollier C. (2002a), "Discounting an uncertain future," Journal of Public Economics, 85(2), p. 149-166.

Gollier C. (2002b), "Time Horizon and the Discount Rate," Journal of Economic Theory, 107(2), p. $463-473$.

Groom, B., Hepburn C., Koundouri P., Pearce D. (2005), "Discounting the Future: The Long and the Short of it", Environmental and Resource Economics, 32(4), p. 445-493.

Howarth R. (1991a), "Intergenerational competitive equilibria under technological uncertainty and an exhaustible resource constraint," Journal of Environmental Economics and Management, 21(3), p. 225-243.

Howarth R. (1991b), "Intertemporal equilibria and exhaustible resources: an overlapping generations approach," Ecological Economics, 4(3), p. 237-252.

Howarth R., Norgaard R. (1990), "Intergenerational Resource Rights, Efficiency, and Social Optimality," Land Economics, 66(1), p. 1-11.

Howarth R., Norgaard R. (1992), "Environmental Valuation under Sustainable Development," American Economic Review, 82(2), p. 473-477. 
Howarth R., Norgaard R. (1993), "Intergenerational transfers and the social discount rate," Environmental and Resource Economics, 3(4), p. 337-358.

John A., Pecchenino R. (1994), "An Overlapping Generations Model of Growth and the Environment", The Economic Journal 104, pp. 1393-1410.

John A., Pecchenino R., Schimmelpfennig D., Schreft S. (1995), "Short-Lived Agents and the Long-Lived Environment", Journal of Public Economics 58, 127-141.

Krautkraemer J.K., Batina R.G. (1999), "On Sustainability and Intergenerational Transfers with a Renewable Resource," Land Economics, 75(2), p. 167-184.

Kunreuther H., Easterling D. (1990), "Are Risk-Benefit tradeoffs possible in siting hazardous facilities?" American Economic Review Papers and Proc., 80, p. 252-256.

Li C., Lofgren K. (2000), "Renewable Resources and Economic Sustainability: A Dynamic Analysis with Heterogeneous Time Preferences," Journal of Environmental Economics and Management, 40(3), p. 236-250.

Marini G., Scaramozzinno P. (1995), "Overlapping Generations and Environmental Control", Journal of Environmental Economics and Management 29, pp. 64-77.

Nordhaus W. (2007), "A Review of the Stern Review on the economics of climate change," Journal of Economic Literature, 45(3), p. 686-702.

Pearce D., Groom B., Hepburn C., Koundouri P. (2003), "Valuing the Future: Recent Advances in Social Discounting," World Economics, 4(2), p. 121-141.

Portney P.R., Weyant J.P. (1999), Discounting and Intergenerational Equity, Resources for the Future.

Riddel M., Schwer R.K. (2006), "Winners, Losers, and the Nuclear-Waste Dilemma", Environmental and Resource Economics (22), pp. 317-338.

Samuelson P.A. (1958), "An Exact Consumption-Loan Model of Interest with or without the Social Contrivance of Money," Journal of Political Economy, 66(6), p. 467-482.

Schubert K. (2006), "Discounting and the environment," Louvain Economic Review, 72(2), p. 157-177.

Shrader-Frechette K. (1994a), "Unsafe at Any Depth: Geological Methods, Subjective Judgments, and Nuclear Waste Disposal," Boston Studies in the Philosophy of Science, 54, p. 501-524.

Shrader-Frechette K. (1994b), "Equity and nuclear waste disposal," Journal of Agricultural and Environmental Ethics, 7(2), p. 133-156.

Solow R.M. (1974), "The Economics of Resources or the Resources of Economics," American Economic Review, 64(2), p. 1-14.

Solow R.M. (1986), "On the Intergenerational Allocation of Natural Resources," Scandinavian Journal of Economics, 88(1), p. 141-149. 
Stern N. (2006), Stern Review on The Economics of Climate Change, HM Treasury, London.

Taebi B. (2012), "Intergenerational Risks of Nuclear Energy," in Handbook of Risk Theory, Springer, p. 295-318.

Tsur Y., Zemel A. (1996), "Accounting for global warming risks: resource management under event uncertainty," Journal of Economic Dynamics and Control, 20, p. 1289-1305.

Tsur Y., Zemel A. (1998), "Pollution control in an uncertain environment," Journal of Economic Dynamics and Control, 22, p. 967-975.

Tsur Y., Zemel A. (2008), "Regulating environmental threats," Environmental and Resource Economics, 39, p. 297-310.

Valente S. (2011), "Intergenerational externalities, sustainability and welfare - The ambiguous effect of optimal policies on resource depletion," Resource and Energy Economics, 33, p. 9951014 .

von Amsberg J. (1995), "Excessive Environmental Risks: An Intergenerational Market Failure," European Economic Review, 39(8), p. 1447-1464.

Weitzman M.L. (1998), "On the welfare significance of national product under interest-rate uncertainty," European Economic Review, 42(8), p. 1581-1594.

Weitzman M.L. (2007), "A review of the Stern review of the economics of climate change," Journal of Economic Literature, 45(3), p. 703-724.

Zhang, J.J. (1999), "Environmental Sustainability, Nonlinear Dynamics and Chaos", Economic Theory 14, pp. 489-500.

\section{Appendix}

The competitive steady state equilibrium is such that $k_{t+1}=k_{t}=k^{*}$. It is defined by the following system:

$$
\mid \begin{aligned}
& f_{k}^{\prime}=1+r^{*} \\
& f\left(k^{*}\right)-k^{*} f_{k}^{\prime}=w^{*} \\
& \left(1-\tau^{w}\right) w^{*}-T^{y}=c^{y^{*}}+s^{*} \\
& c^{o^{*}}=\left(1-\tau^{k}\right)\left(1+r^{*}\right) s^{*} \\
& k^{*}=s^{*} \\
& \frac{u_{c o}^{\prime} o}{u_{c y}^{\prime}}=\frac{1}{\left(1+r^{*}\right)\left(1-\tau^{k}\right)} \\
& \left(1+r^{*}\right) \tau^{k} s^{*}+\tau^{w} w^{*}+T^{y}=\sigma \alpha \phi k^{*} \\
& Q^{*}=\frac{\tilde{Q}}{h}-\frac{\phi}{h}[1-\alpha(1-E(\tilde{\gamma}))] k^{*}
\end{aligned}
$$


The planner maximization programme is:

$$
\begin{aligned}
& L_{t}\left(c_{t-1}^{y}, c_{t}^{o}, k_{t}, Q_{t-1}\right)= \\
& \sum_{t=1}^{+\infty} \delta^{t-1}\left[u\left(c_{t-1}^{y}, c_{t}^{o}\right)\right. \\
& +\theta z\left(\tilde{Q}+[1-h] Q_{t-1}-(1-\alpha) \phi k_{t-1}-E(\tilde{\gamma}) \alpha \phi k_{t-i-1} ;\right. \\
& \left.\left.\quad \tilde{Q}+[1-h] Q_{t-2}-(1-\alpha) \phi k_{t-2}-E(\tilde{\gamma}) \alpha \phi k_{t-i-2}\right)\right] \\
& -\sum_{t=1}^{+\infty} \delta^{t-1} \lambda_{1, t-1}\left[k_{t}-f\left(k_{t-1}\right)+c_{t-1}^{y}+c_{t-1}^{o}+\sigma_{t-1} \alpha \phi k_{t-1}\right] \\
& -\sum_{t=1}^{+\infty} \delta^{t-1} \lambda_{2, t-1}\left[Q_{t-1}-\tilde{Q}-[1-h] Q_{t-2}+(1-\alpha) \phi k_{t-2}+E(\tilde{\gamma}) \alpha \phi k_{t-i-2}\right]
\end{aligned}
$$

The necessary optimal conditions are given by:

$$
\mid \begin{aligned}
& \frac{\partial L_{t}(.)}{\partial k_{t}}=0 \Leftrightarrow \lambda_{1}=\frac{\Theta\left(\lambda_{2} \delta+\theta z^{\prime}(1+\delta)\right)}{f^{\prime}-\sigma \alpha \phi-\frac{1}{\delta}} \\
& \frac{\partial L_{t}(.)}{\partial Q_{t-1}}=0 \Leftrightarrow \lambda_{2}=\frac{(1-h) \theta z^{\prime}(1+\delta)}{1-\delta(1-h)} \\
& \frac{\partial L_{t}(.)}{\partial c_{t-1}^{y}}=0 \Leftrightarrow \lambda_{1}=u_{c^{y}}^{\prime} \\
& \frac{\partial L_{t}(.)}{\partial c_{t}^{o}}=0 \Leftrightarrow \lambda_{1}=\frac{1}{\delta} u_{c^{o}}^{\prime} \\
& \frac{\partial L_{t}(.)}{\partial \alpha}=0 \Leftrightarrow \lambda_{1}=\frac{1-E(\tilde{\gamma}) \delta^{i}}{\sigma}\left(\theta z^{\prime}(1+\delta)+\delta \lambda_{2}\right)
\end{aligned}
$$

